\title{
PHƯƠNG PHÁP TRẢI NGHIỆM TRONG DẠY HỌC TIẾNG ANH THEO HỨ̛́NG TIẾP CẬN CDIO TẠI TRUNG TÂM NGOẠI NGỬ TRƯỜNG ĐẠI HỌC THỦ DÀU MỘT
}

\author{
Trịnh Huỳnh Chấn ${ }^{(*)}$
}

(*) Thạc sĩ. Truoòng Đại học Thủ Dầu Một. Email: chanth@tdmu.edu.vn

DOI: $10.37550 /$ tdmu.CFR/2021.01.123

\section{Tóm tắt}

CDIO là một giải pháp phát triển giáo dục toàn vẹn trong thời đại ngày nay. Có nhiều phuơng pháp dạy học tích cưc dược đề ra, trong đó dạy học trải nghiệm là một phưong pháp gắn kết người học với thực tiễn một cách sâu sắc nhất, giúp cho nguời hoc co* hội phát triển toàn diện các kĩ năng. Tiếng Anh là môn hoc cần được trải nghiệm để giao tiếp thuờng xuyên và chủ động. Bài viết này tác giả muốn nêu lên cách thức thưc hiện tổ chưc dạy học trải nghiệm ngay trong các tiết học tiếng Anh trên lớp theo huớng tiếp cận CDIO mà tác giả đã thục hiện tại Trung tâm Ngoại ngũ Trương Đại học Thủ Dầu Một.

Từ khóa: Phuơng pháp trải nghiệm, dạy học Tiếng Anh, CDIO

\section{1. Đặt vấn đề}

Tiếng Anh là một môn học bắt buộc trong chương trình học tập của học sinh, sinh viên Việt Nam. Ở môi trường Đại học, Tiếng Anh là một trong những tri thức quan trọng làm hành trang để sinh viên (người lao động tương lai) tiếp cận và hòa nhập yêu cầu của thị trường lao động trong bối cảnh hội nhập.

Trong quá trình hội nhập, toàn cầu hóa như hiện nay, tại hầu hết các quốc gia trên thế giới, tiếng Anh là một ngôn ngữ được sử dụng phổ biến. Nếu không có nền tảng tiếng Anh tốt thì các thế hệ tương lai sẽ khó bắt kịp được với các xu thế mới trên thế giới, sự phát triển của công nghệ và mất đi những cơ hội về việc làm. TS. Lê Thẩm Dương đã từng nói trong hội thảo "Định vị bản thân, làm chủ cuộc đời" rằng: "Tất cả các biên giới về bộ tộc, tôn giáo, chủng tộc và ý thức hệ tồn tại là vì loài ngườ đã tạo ra chúng. Việc học hỏi xuyên biên giới có nghĩa là "phá vỡ" các biên giới này để chúng ta nhu các nhà du hành vũ trụ, có thể nhìn thấy một tổng thể hoàn chỉnh. Tiếng Anh là một trong nhũng "vũ khi" để phá võ các biên giới, giới hạn đó” [7]. Vì vậy học tiếng Anh là vô cùng cần thiết.

Tuy nhiên thực tế học tiếng Anh ở Việt Nam lại còn rất nhiều bất cập. Tiếng Anh được đưa vào giảng dạy từ rất sớm: từ chương trình lớp 1 (một số địa phương khó khăn thì 
được đưa vào từ chương trình lớp 3), và được học xuyên suốt đến hết lớp 12. Sinh viên khi vào học đại học lại được tiếp tục học Anh văn trong chương trình. Song trình độ tiếng Anh của các bạn sinh viên lại rất hạn chế: khó khăn trong giao tiếp, kết quả học tập hay kết quả của các kì thi cũng không cao. Vậy nguyên nhân của vấn đề là từ đâu? Có thể khẳng định rằng nguyên nhân chính là phương pháp dạy và học chưa phù hợp.

Với sự tiếp cận với CDIO - một giải pháp giáo dục hiện đại, giảng viên của Trung tâm Ngoại ngữ Trường Đại học Thủ Dầu Một đã áp dụng rất nhiều phương pháp dạy học mới, phương pháp dạy học chủ động, phương pháp dạy học trải nghiệm... nhằm đạt đến kết quả cao nhất, giúp sinh viên khi ra trường có thể tiếp cận nhanh chóng, đáp ứng được các yêu cầu của xã hội.

\section{Tiếp cận CDIO và dạy học trải nghiệm}

CDIO là cụm từ viết tắt trong tiếng Anh của: Conceive (hình thành ý tuơơng) - Design (thiết kế ý tuởng) - Implement (thực hiện ý tuơơng) - Operate (vận hành ý tuởng). CDIO được khởi xướng vào năm 2000 bởi học viện Công nghệ Masachusetts (MIT) hợp tác với 3 trường khác ở Thụy Điển [8]. Mục tiêu ban đầu là đào tạo một đội ngũ kỹ sư phù hợp với nhu cầu thực tế của xã hội dựa trên tiêu chí của các nhà tuyển dụng yêu cầu. Với phương pháp xây dựng chương trình đào tạo phù hợp với chuẩn đầu ra. Sinh viên trong chương trình đào tạo theo cách tiếp cận CDIO được phát triển và cần đạt được 4 năng lực chính (hay còn gọi là chuẩn đầu ra) khi tốt nghiệp, bao gồm: Khối kiến thức (lý thuyết) và lập luận ngành; Các kỹ năng và phẩm chất cá nhân và nghề nghiệp; Các kỹ năng và phẩm chất xã hội; Năng lực áp dụng kiến thức vào thực tiễn (năng lực C-D-I-O) đặt trong bối cảnh xã hội và doanh nghiệp. Giải pháp CDIO giúp sinh viên có được các kỹ năng cứng và mềm cần thiết khi ra trường và đáp ứng được yêu cầu của xã hội cũng như bắt nhịp được với những thay đổi của môi trường, thậm chí là có thể dẫn dắt sự thay đổi đó [4].

Giải pháp CDIO được áp dụng ở Việt Nam bắt đầu từ năm 2008 với sự khởi xướng của 2 trường đại học là Đại học Quốc gia Hà Nội và Đại học Quốc gia Hồ Chí Minh. Từ việc áp dụng một cách linh hoạt, sáng tạo giải pháp CDIO trong đào tạo không chỉ trong khối ngành kỹ thuật mà còn trong các khối ngành khác đã đạt được kết quả khả quan. Bước đầu là xác định được chuẩn đầu ra để xây dựng chương trình đào tạo thích hợp theo chuẩn $\mathrm{CDIO}$, phù hợp với nhu cầu của xã hội nói chung và nhà tuyển dụng nói riêng. Nhờ những kết đó, hàng loạt các trường khác đã bắt đầu tìm hiểu, áp dụng giải pháp CDIO ở các mức độ khác nhau như trường Ngoại ngữ - Tin học Thành phố Hồ Chí Minh, Đại học Thái Nguyên, Đại học Sư phạm Kĩ Thuật Thành phố Hồ Chí Minh,...và Đại học Thủ Dầu Một.

Về bản chất, $\mathrm{CDIO}$ là một giải pháp nâng cao chất lượng đào tạo, đáp ứng yêu cầu xã hội trên cơ sở xác định chuẩn đầu ra, từ đó thiết kế chương trình và kế hoạch đào tạo. Quy trình này được xây dựng một cách khoa học, hợp lí, logic, có thể áp dụng cho nhiều lĩnh vực đào tạo khác nhau [4].

Mục tiêu đào tạo theo CDIO là hướng tới việc giúp sinh viên có được kĩ năng cứng và mềm cần thiết khi ra trường, nhằm đáp ứng yêu cầu, đòi hỏi của xã hội, cũng như bắt kịp được những thay đổi rất nhanh của thực tiễn đời sống. Sinh viên có thể làm chủ trong việc 
học, điều chỉnh phương pháp học theo hướng tích cực [4].

Một trong những đặc điểm nổi bật của phương pháp đào tạo theo CDIO là học tập tích hợp và trải nghiệm chủ động. Theo cách tiếp cận $\mathrm{CDIO}$, sinh viên sẽ trang bị các kĩ năng cá nhân, kĩ năng giao tiếp, kĩ năng kiến tạo sản phẩm, xây dựng quy trình và hệ thống cùng với kiến thức chuyên ngành trong chương trình đào tạo thực hành chuyên nghiệp. Giảng dạy và học tập dựa trên các phương pháp học tập trải nghiệm chủ động theo mô hình CDIO gồm các phương pháp thu hút sự tham gia của $\mathrm{SV}$ một cách trực tiếp vào các hoạt động tư duy và giải quyết vấn đề. Mặc dù có ít sự truyền đạt thông tin một cách thụ động, nhưng lại nhấn mạnh nhiều hơn vào việc thu hút sinh viên sự tham gia vào khám phá, ứng dụng, phân tích, và đánh giá các ý tưởng [8].

Như vậy, thực chất của dạy học trải nghiệm là thực hiện nguyên lí "học đi đôi với hành". Điều này được khẳng định một lần nữa trong khái niệm về hoạt động trải nghiệm của PGS.TS Đinh Thị Kim Thoa: "Hoạt động giáo dục thông qua sự trải nghiệm và sáng tạo của cá nhân trong việc kết nối kinh nghiệm học được trong nhà trường với thực tiễn đời sống mà nhờ đó các kinh nghiệm được tích lũy và dần chuyển hóa thành năng lực" [6].

Bản chất của dạy học trải nghiệm là hoạt động giáo dục được tổ chức theo con đường gắn kết lí thuyết với thực tiễn, tạo điều kiện cho học sinh được tham gia trực tiếp và làm chủ thể hoạt động (tự lên kế hoạch, chủ động xây dựng chiến lược học tập, nó nằm trong mô hình: Conceive (hình thành ý tuởng) - Design (thiết kế ý tuởng) - Implement (thưc hiện ýtuoơng) - Operate (vận hành ý tương)), từ đó tạo nên sự thống nhất giữa nhận thức và hành động, hình thành phát triển cho học sinh niềm tin, tình cảm và năng lực cần có của công dân trong xã hội hội nhập (phát triển toàn diện nhân cách học sinh)

Dấu hiệu đặc trưng của hoạt động trải nghiệm là: 1) Học sinh tham gia trực tiếp vào từng hoạt động học tập; 2) Tính chủ động của học sinh trong kế hoạch và hoạt động cá nhân; 3) Tính hợp tác, tương tác trong hoạt động giữa các học sinh; 4) Tính tiếp cận với môi trường trong và ngoài nhà trường; 5) Tính sáng tạo để thích ứng và tạo ra những giá trị mới cho bản thân (kiến thức, kĩ năng, tình cảm).

Như vậy, dạy học trải nghiệp theo hướng tiếp cận CDIO được xem như một sáng kiến mới cho giáo dục, một hệ thống phương pháp, hình thức tích lũy kiến thức, kĩ năng trong việc nâng cao chất lượng đào tạo đại học nhằm đáp ứng yêu cầu của doanh nghiệp, xã hội.

\section{Dạy học Tiếng Anh theo hướng tiếp cận CDIO tại Trung tâm Ngoại ngữ Trường Đại học Thủ Dầu Một}

\section{1. Đôi nét về đào tạo Tiếng Anh tại Trung tâm Ngọ̣i ngũu Trường Đại học Thủ Dầu $M \hat{o} t$}

Trung tâm Ngoại ngữ Trường Đại học Thủ Dầu Một là một đơn vị trực thuộc Trường Đại học Thủ Dầu Một, có nhiệm vụ và chức năng đào tạo ngoại ngữ cho sinh viên không chuyên của Trường. 
Hiện nay Trung tâm Ngoại ngữ Trường Đại học Thủ Dầu Một đào tạo 4 loại ngoại ngữ: tiếng Anh, tiếng Trung, tiếng Pháp, tiếng Hàn. Trong đó số lượng sinh viên tham gia đăng kí học tiếng Anh là đông nhất, chiếm trên 70\%.

Chương trình đào tạo tiếng Anh không chuyên gồm: TDMU-EPT, IELTS, Tiếng Anh thương mại, tiếng Anh tổng quát,...

Phương thức đăng kí: tự nguyện.

Hình thức đăng kí: online.

\subsection{Dạy học Tiếng Anh theo huớng tiếp cận CDIO tại Trung tâm Ngoại ngũ Truò̀ng Đại học Thủ Dầu Một}

Cũng như các môn học khác, dạy học Tiếng Anh được thực hiện với nhiều phương pháp nhằm đem lại hiệu quả cao nhất của tiến trình dạy học. Song với sự tiếp cận với phương pháp giảng dạy hiện đại của $\mathrm{CDIO}$, các phương pháp dạy học như: thảo luận trong nhóm nhỏ, tranh luận, làm demo... đặc biệt là dạy học bằng trải nghiệm được đẩy mạnh, thực hiện ở Trung tâm Ngoại ngữ Trường Đại học Thủ Dầu Một.

Thực tế hiện nay, trong sự phát triển mạnh mẽ của nền kinh tế quốc tế, sự hội nhập và mở cửa của Việt Nam đã và đang tạo điều kiện rất lớn cho các nhà đầu tư, những tập đoàn kinh tế lớn đầu tư vào Việt Nam, kéo theo số lượng người nước ngoài đến làm việc và sinh sống tại Việt Nam ngày càng đông. Bên cạnh đó là sự phát triển của du lịch cũng làm cho những du khách nước ngoài đến Việt Nam ngày càng nhiều. Đó là cơ hội cho sinh viên được thực hiện giao tiếp trực tiếp với người nước ngoài, và là điều kiện tốt nhất để sinh viên tham gia trải nghiệm. Tuy nhiên không phải tất cả sinh viên đều có cơ hội gặp gỡ và trao đổi trực tiếp với người nước ngoài để thực hành giao tiếp. Những cơ hội khác trong xã hội hiện đại, ví dụ như mạng xã hội cũng sẽ tạo điều kiện cho sinh viên thực hiện trải nghiệm. Đó là những hình thức học tập thực tế, học tập ngoài trường, sinh viên có thể chủ động thực hiện theo điều kiện có thể. Nhưng với giáo viên, nó lại là bị động, phụ thuộc nhiều vào ý thức tự giác thực hành của sinh viên. Để chủ động cho sinh viên học tập trải nghiệm, giáo viên có thể tổ chức ngay trong buổi dạy của mình trên lớp, tích cực cho sinh viên trực tiếp hoạt động thực hành, giao tiếp với thầy cô và bạn bè.

Phương pháp thực hiện:

Buớc 1: Trắc nghiệm trước bài giảng.

Mục đích của trắc nghiệm trước bài giảng là để nắm được tình hình, khả năng học tập của sinh viên để điều chỉnh mục tiêu và phương pháp dạy học trong tiết dạy học đó. Ví dụ: Để dạy cách chuyển từ 1 câu chủ động sang bị động ở thì hiện tại hoàn thành, giáo viên cho sinh viên làm 1 số câu trắc nghiệm:

Choose the best answer:

1. Romio and Juliet by Shakespeare.
A.
was written
B. is written
C. is being written
2.
The house at the moment.
A.
is painted
B. is being painted
C. was painted 
3. Somebody accused me of stealing money

A. I was accused by somebody of stealing money

B. I was accused of stealing money

C. I was accused of stealing money by somebody

D. I was accused stealing money

Buớc 2: Giáo viên nêu vấn đề vào bài giảng.

Nêu vấn đề vào bài giảng cũng là một trong những yếu tố góp phần vào sự thành công của bài giảng, tạo nhu cầu hứng thú học tập cho sinh viên. Có rất nhiều cách nêu vấn đề vào bài giảng, nhưng nêu vấn đề vào bài giảng theo cách tạo ra yếu tố mâu thuẫn trong vấn đề nội dung bài học là cách gây sự tò mò, hứng thú tìm hiểu nhất đối với sinh viên. Ví dụ: Để dạy sự hòa hợp giữa chủ ngữ và động từ trong tiếng $A n h$, giáo viên hỏi sinh viên: tại sao "A number of” đi với động từ số nhiều nhưng “The number of" lại đi với động từ số ít?

\section{Bước 3: Chuyển giao nhiệm vu cu thể}

Hướng dẫn sinh viên thực hiện các hoạt động để tìm tòi tri thức mới. Cụ thể là áp dụng đa dạng các hình thức tổ chức dạy học theo nguyên tắc tăng cường tính thực hành, hành động tương tác, hoạt động nhóm, giải quyết vấn đề, .v.v., như thảo luận nhóm, semina,... Sự đa dạng về hình thức dạy học này tạo điều kiện cho sinh viên vận dụng những tri thức, sự hiểu biết của mình vào bài học, trao đổi và thực hành ngôn ngữ với bạn bè, giáo viên.

Ví dụ: Khi dạy kỹ năng nói theo cặp (work in pair), giáo viên giao nhiệm vụ cụ thể cho sinh viên là phải nói tiếng Anh với người ngồi bên cạnh về một chủ đề bài học. Hoặc khi dạy về những cảnh đẹp thiên nhiên, giáo viên cho sinh viên làm việc theo nhóm để nêu lên những điểm du lịch tự nhiên ở địa phương mà sinh viên biết; miêu tả sơ bộ về cảnh đẹp tự nhiên nơi đó (Conceive (hình thành ýy tuoơng) - Design (thiết kế ý tưởng) - Implement (thưc hiện ý tuởng) - Operate (vận hành ý tuởng) trong CDIO)

Với nhiệm vụ này, sinh viên phải thực hành trao đổi với nhau bằng tiếng Anh với những tình huống giả định mà chúng phải tự thiết kế ra (Conceive (hình thành ýy tưởng) Design (thiết kế ý tuơơng)).

Cách thực hiện này có giá trị rất lớn trong dạy học tiếng Anh: nó giúp cho sinh viên chủ động nhận thức tri thức, mạnh dạn trong thiết kế và thực hiện.

Bước 4: Trắc nghiệm sau bài giảng.

Mục đích là để đánh giá kết quả hoạt động đạt được sau bài học, so sánh kế quả đó với kết quả ban đầu khi thực hiện trắc nghiệm tiền bài giảng.

Ví dụ: Vẫn bài học về cách chuyển từ câu chủ động sang bị động, sau khi thực hiện các hoạt động để đạt kết quả học tập của bài học, giáo viên có thể đặt câu hỏi để đánh giá kết quả học tập như:

Các bạn có thể cho thầy biết các nhận xét sau đúng hay sai:

1. Cấu tạo của câu bi động ở thì hiện tại hoàn thành cũng giống cấu tạo của câu bị động ở các thì khác. 
2. Cấu tạo của câu bị động ở thì hiện tại hoàn thành khác với cấu tạo của câu bị động ở các thì khác ở động từ "to be".

3. Động từ chính trong câu bị động ở thì hiện tại hoàn thành vẫn chia giống như động từ chính ở những thì khác.

Buớc 5: Kết luận, đánh giá cuối bài, và huớng dẫn học tập ở nhà.

Đây là quy trình cuối cùng trong bài lên lớp của giáo viên. Mặc dù quy trình này chiếm một thời lượng rất nhỏ trong tiết học, nhưng lại có ý nghĩa rất lớn: giảng viên rút ra những kết luận cần thiết sau cả bài học để sinh viên nắm được những vấn đề cốt lõi, những tri thức chính, trọng tâm của bài học; sinh viên và giảng viên đánh giá lại toàn tiết học về nội dung, tinh thần, thái độ học tập của các thành viên trong lớp; nhắc nhở và dặn dò sinh viên cách học tập, những nội dung học tập cần được bổ sung, thực tập thêm sau tiết học.

\section{Kết luận}

Dạy học trải nghiệm theo hướng tiếp cận CDIO là một hình thức dạy học tích cực, tăng cường tính thực hành cho sinh viên. Nó mang lại giá trị lớn trong dạy và học nói chung và trong dạy và học tiếng Anh nói riêng.

Tiếng Anh là môn học về ngôn ngữ, do vậy việc thực hành, vận dụng thường xuyên là vấn đề cấp bách, cần thiết. Nó có thể thực hiện trực tiếp với người nước ngoài, qua mạng xã hội, ... Nhưng chủ động nhất vẫn là tăng cường thực hành ngay trong những tiết học Anh văn trên lớp.

Để thực hiện thành công, mang lại hiệu quả cao nhất trong dạy học tăng cường tính thực hành, tiết học trên lớp của giảng viên cũng nên thực hiện theo những quy trình nghiêm ngặt, chặt chẽ, khoa học.

\section{Tài liệu tham khảo}

[1] Đại học Quốc gia Thành phố Hồ Chí Minh ( 2012), Hội nghị CDIO toàn quốc 2012 "Đào tạo đáp ứng nhu cầu xã hội và hội nhập quốc tế: Mô hình CDIO". Đại học Quốc gia Thành phố Hồ Chí Minh.

[2] Đại học Ngoại ngữ - Tin học Thành phố Hồ Chí Minh (HUFLIT) (2011), Quy trình xây dưng chương trình đào tạo theo phương pháp tiếp cận CDIO, Đại học Ngoại ngữ -Tin học Thành phố Hồ Chí Minh.

[3] Andrew Marchand (2015), Instruction Skills Workshop, Tài liệu tập huấn các kỹ năng giảng dạy.

[4] Đỗ Thế Hưng, 2010, Dạy học theo tiếp cận "CDIO” trong đào tạo giáo viên kĩ thuật trình độ đại học, Luận án Tiến sĩ.

[5] Nguyễn Thành Hải, Phùng Thúy Phượng, Đồng Thị Bích Thủy, 2010. Phương pháp học tập chủ động và trải nghiệm, đạt các chuẩn đầu ra theo CDIO. Hội thảo CDIO- Đại học Quốc Gia Tp. HCM.

[6] Đinh Thị Kim Thoa (2015), Xây dựng chuoong trình hoạt động trải nghiệm sáng tạo trong chuoong trình giáo duc phổ thông mới, Kỉ yếu hội thảo quốc tế, Học viện Quản lí giáo dục. 
[7] TS. Lê Thẩm Dương (2015), "Định vị bản thân, làm chủ cuộc đời”, Hội thảo quốc gia.

[8] http://www.cdio.org/cdio-history, truy cập ngày 24/8/2016 
